\title{
Introducing a global planetary ecosystem accounting in the wake of the Amazon Forest fires
}

Zaheer Allam (1) 1,2,3凶 , David S. Jones ${ }^{4,5} \&$ Can Biyik ${ }^{6}$

Since the 19th century, rapid urbanisation coupled with a demographic boom has increased pressures on the global exploitation of natural resources leading to an array of issues at planetary scale. Even though there have been significant ecologically driven human policy efforts, with frameworks addressing ecosystem accounting and management, such are principally constricted at sub-global levels; being regionally focussed, and hence lacking both cohesivity and accountability. Resource management viewed through this lens leads to a number of geopolitical factors as demonstrated recently with the Amazon Forest fires. This incident witnessed calls from numerous countries calling for rapid remediation even though their own policies are harbingers of equally damaging the environments through other means. This disparity in resource accounting and management on a planetary scale is apparent from diverse local and regional groups and needs to be addressed in order to sustain a truly sustainable and liveable ecosystem and their failures in realising a viable ecosystem accounting system. This perspective paper explores this theme and proposes a 'Global Planetary Ecosystem Accounting' system based on the principle that ecologically sensitive areas benefiting the global ecosystem need to be economically weighted and its preservation equated to a revenue-generating activity.

\footnotetext{
${ }^{1}$ Institute for Sustainable Futures, University of Technology Sydney, Sydney 2007, Australia. ${ }^{2}$ Chaire Entrepreneuriat Territoire Innovation (ETI), Groupe de Recherche en Gestion des Organisations (GREGOR), IAE Paris - Sorbonne Business School, Université Paris 1 Panthéon-Sorbonne, 75013 Paris, France. ${ }^{3}$ Live + Smart Research Lab, School of Architecture and Built Environment, Deakin University, Geelong, VIC 3220, Australia. ${ }^{4}$ Wadawurrung Traditional Owners Aboriginal Corporation, 86 Mercer Street, Geelong, VIC 3220, Australia. ${ }^{5}$ Cities Research Institute, Griffith University, 170 Kessels Road, Nathan, QLD 4111, Australia. ${ }^{6}$ Department of Civil Engineering, Faculty of Engineering and Natural Sciences, Ankara Yıldırım Beyazıt University, 06010 Ankara, Turkey.

凶email: zaheerallam@gmail.com
} 


\section{Introduction}

'Tribes from the Amazon have called for urgent action to protect the world's largest rainforest in a formal motion to the International Union for Conservation of Nature (IUCN), to be considered at its global congress in France next month' [in September 2021] (Moloney, 2021).

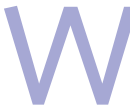

e know that the Amazon Forests play a key role in mediating and regulating the Earth's climate by filtering, absorbing, and storing planet-heating carbon dioxide. Deforestation is largely fuelled by illegal logging and gold mining availed by landscape-scale fires, as well as land clearance and burning to enable soy and beef farming in Brazil to plant coco crops in Colombia and Peru. In moving the above motion, the Coordinating Body for Indigenous Organisations of the Amazon Basin (COICA), an IUCN Member, the COICA General Co-ordinator José Gregorio Diaz Mirabel has observed that with minimal political and economic voice, Indigenous Peoples from the Amazon Basin's nine countries often struggle to be heard on the global stage where decisions affect their lands and waters and receive little international funding. Diaz stated that 'The call we will make is that finance should go to Indigenous People who conserve and protect the territory' (Moloney, 2021). But, how do we as a society craft a multi-political boundary ecosystem accounting model to validate and support this endeavour?

The world has experienced an unprecedented increase in consumption, both of natural resources and artificially manufactured products, and these have had far-reaching ramifications. In particular, natural resources are under immense pressure due to wanton and uncontrolled exploitation, as well as from increased pollutions. This conclusionary thread draws upon the recent past evidence, in the shadow of this global exponential demographic boom and increased urbanisation rates, with the majority of the human population now seen to be preferring urban habitats. Statistics on these two phenomena are captured in an United Nation's report (United Nations, 2018a), which underscores that these two patterns have led to the conspicuous consumption of resources especially those related to water, energy, forests and marine resources. Tajrin and Hossain (2018) note that the consumption of these resources in cities is insatiable and that there is no foreseeable end to this devouring, noting that over $2 / 3$ of the world's population is expected to find abodes in cities by 2050 (United Nations, 2018b).

The unfortunate truth about these trends is that they continually accentuate a disbalance on a global planetary scale, where large areas (especially 'natural' reserves) are being put at risk in the efforts to accommodate and settle densely populated urban areas, and the actions being taken on this are critically insufficient. We say 'natural' because all global landscapes have experienced the conscious or unconscious of the human hand in transforming, manipulating, or intergenerationally managing these tracts that are seemingly 'natural' today. Thus, 'landscape is a cultural construct, ['that largely manmade tapestry'], a mirror of our memories and myths encoded with meanings which can be read and interpreted' (Lowenthal, 1975; Taylor, 2017).

In particular, as $\mathrm{Tu}$ (2017) notes, of the many issues that emanate from this disbalance, global attention is seen to be passionately focused upon an emissions perspective and other dimensions that are equally important in sustaining thriving ecosystems are relegated to lower levels of concern. This is evidenced in the numerous calls from different researchers, both from regional and international spheres, calling for decarbonisation (IRENA, 2018; Kelsey and Meckling, 2018; Mazzucato and Semieniuk, 2018; USAID/NREL, 2018) and/or even planetary emission accounting systems (La Notte et al., 2019; Vargas et al., 2018), But there is little, or no, high level calls on other dimensions; even though they are of equal importance for sustaining human liveability (Ajani et al., 2013).

Thus, it is evident that recent calls about decarbonisation have not been universally embraced, especially in regard to the adoption of a conventional, cohesive ecosystem model. The friction here emanates from a number of issues including the lack of goodwill in having an integrated system that satisfies both ecological needs as well as economic dimensions. While this is globally understood, there are strong societal preferences in advance of ecological imperatives, leading to disbalances that are often criticised by different quarters advocating for singular motives. This friction is underpinned by geopolitical influences driving climate change, especially the narratives from powerful economies that are competing to take charge of the reigns of global power (Scott et al., 2016). In addition, some of those economies interpret decarbonisation and reduction of emissions as threats in disrupting their existing economic models and policies. Thus, there has been noticeable reticence, mainly from developed economies, for a global consensus on climate change agreements (Zhang et al., 2017). On the other hand, increasing societal pressures are leading to global movements, such as Greta Thunberg's 'Youth for Climate', calling for deep policy reversals, and aligning with the recommendations of the Intergovernmental Panel on Climate Change (IPCC, 2021). But, as these climate change and planetary ecosystem tensions continue, the consequence from applied inaction is becoming increasingly evident with farreaching implications.

The Amazon Forest fires, in this context, offer an interesting case study. Even though this environmental change does not result from conscious climate change human activities, the Amazon traditionally plays a critical role in sustaining a healthy ecosystem through decarbonisation. The fires are a threat to this balance and oxygenation not only to that ecosystem but to the global ecosystem, therefore amplifying the calls by the global community for immediate action (Salazar-Lopez and Allen, 2019; Watts, 2019). Surprisingly, even though that these global community calls are paramount in seeking to protect the ecological stability of this water catching, they will carry little weight in the long run because they do not highlight a need to re-evaluate the current planetary ecosystem management regime. That is, the calls are mainly directed towards the need to address the fires. But, the central theme of the issue is unquestioned: which is, 'what is the economic potential of this natural resource?' Answering this may be an important factor in understanding the direct and indirect benefits and the opportunity costs of natural systems, and their place in immediate, medium- and long-term green economy policies. Additionally, this can help to better frame the economic responsiveness of the Brazilian Government regarding its local policies ill-aligning with national economic agendas leading towards more effective strategies for the safeguarding of the Amazon Forest from dangers linked to unfettered urban development and its associative resource exploitation needs.

Against the above background, this perspective paper explores the case of the Amazon Forest fires and approaches the thematic of natural resource preservation from an economic viewpoint. We would argue for the implementation of a 'Planetary Ecosystem Accounting' model that aims to economically incentivize governments to protect their natural resources primordial in sustaining the global ecosystem. 


\section{Planetary boundaries and ecosystem accounting}

The subject of ecosystem accounting is not new. An analysis of literature suggests that since 2012, several international efforts have focused upon this endeavour, and also a United Nationsauthored System of Environmental-Economic Accounting (SEEA) offering a 'a framework that integrates economic and environmental data to provide a more comprehensive and multipurpose view of the interrelationships between the economy and the environment and the stocks and changes in stocks of environmental assets, as they bring benefits to humanity' (UN, 2020). The SEEA was adopted in June 2021 (UN, 2014). The aim of SEEA is to promote the measurement of environmental activities in relation to their contributions to the economy.

Mäler et al. (2008) note that environmental accounting has been a key tool in assisting researchers to take stock of assets playing a primordial role in sustaining our ecosystem; such as forests, wilderness, wetlands, and others (Hein et al., 2016). Hein et al. argue that the process of ecosystem accounting not only helps to map assets but also offers a coherent and integrated measurement system to map the flow of different ecosystems services into the economy while taking into account related human activities. Further, Vačkářů and Grammatikopoulou (2018) highlight how ecosystem accounting is becoming an important tool in efforts toward sustainability and shifting banking so that economic assets serve as natural capital essential for ecosystem service delivery.

One notable limitation in ecosystem accounting is the absence of information on emissions alone in contrast to dimensions including biodiversity conservation and resource depletion (Mace et al., 2012). A review of literature on ecosystem accounting models, as summarised in Table 1, confirms this.

But, ecosystem accounting models traditionally capture both the physical and monetary data of different ecosystem assets, but little envelopes other dimensions like benefits and beneficiaries of the said assets. By doing this, as noted by Symbol of Statistics Canada (2018), accounting efforts can be expanded beyond geographical boundaries and structural limitations enabling their adoption. Bartelmus (2015) notes that an integrated approach, where different dimensions including emissions, depletion, and conservation efforts are considered together, is recommended especially in the formulation of policies of sustainable economic performance and growth related to ecosystems. According to Bartelmus, doing this would incorporate human well-being within accounting systems. Such is essential because humans play a key role in impacting the ecosystem, both in its degradation and in its conservation, especially when population growth and urbanisation are considered. Mace (2019) supports this by arguing that ecosystem accounting should not only entail the measurement of flows of goods and services and their quality and quantity from the ecosystem into the economy, but that ecosystem accounting should also recognise that ecosystem accounting entails natural capital which is malleable and adaptable that regrow, change and reorganize beyond specific geographical boundaries.

The idea of adopting physical boundaries in the thematic of ecosystem accounting has been viewed as facilitating easy data computation and analysis because data from particular regions can be considered independently. While there is applied practicality in seeking to align with geographical boundaries, some regions with more natural endowment can be seen as benefiting more than the others, and this has prompted region-specific legislations and structures, such as carbon trading or avian migration agreements. This underlines an inequitable distribution of resources towards natural capital and similarly unequal distribution of economic benefits. Both of these demonstrate the need to solve political boundary-specific challenges to ensure global equity. This convenience demands the sharing and merging of data from all regions. However, such an approach can complicate reliable methodologies for data collection between different regions, thereby negating the integration and formulation of a unified cohesive model that would otherwise serve all regions.

In support, Notte and Dalmazzone (2018) argue that most of the planetary ecosystem models, that exclude current ecosystem accounting approaches, are equally significant to ecosystem accounting approaches that incorporate emissions because they also contribute towards economic and human activities. Thus, Notte and Dalmazzone argue that changes in biodiversity composition, within a given region, impacts greatly upon different aspects of an economy including tourism, conservation, agricultural practices, and land use amongst others. For this reason, La Notte et al. (2019) conclude that extending the measurement boundaries and incorporating other dimensions in addition to emissions, would allow the establishment of a causality nexus between the ecosystem assets and the benefits accrued by both economic actors and households.

\section{The case of the Amazon Forest fires}

The case of the Amazon Forest fires and their consequences upon world climate and climate change is not new; rather our Western human memory is short (Blom, 2019).

Blom (2019) has provocatively argued that dramatic changes in the South American landscape management regimes longintergenerationally manipulated and managed by its First

Table 1 Dimensions of ecosystem accounting.

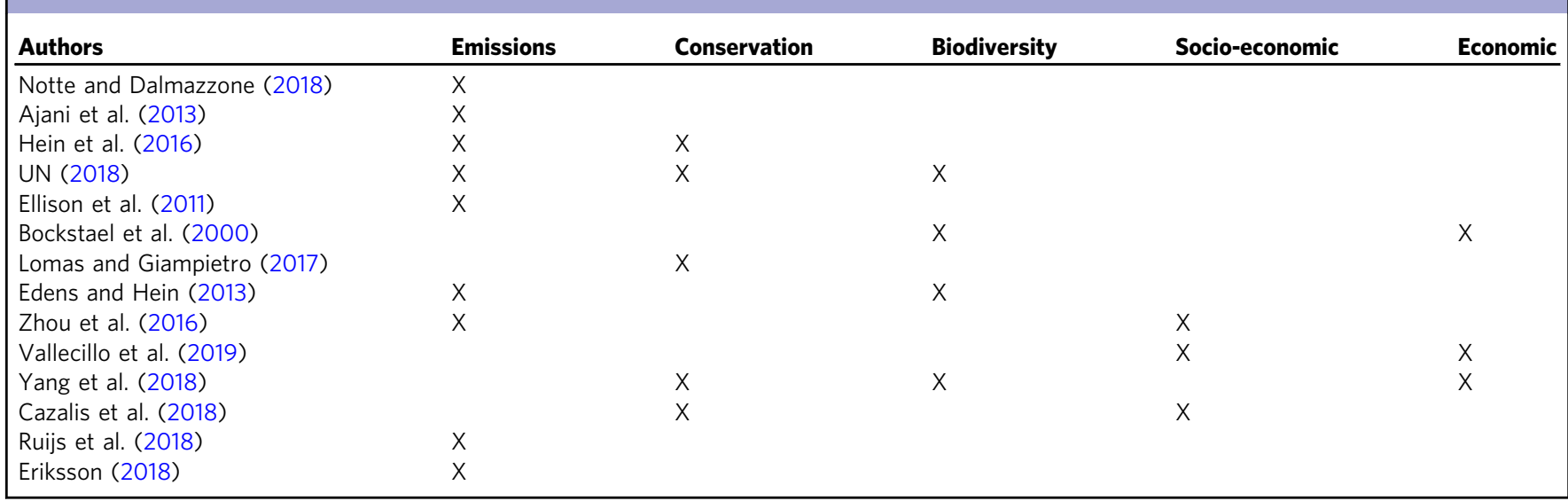


Nations People's changes, collapsed due to Spanish and Portuguese colonialization activities, resulted in the great European climate crisis of the 1600 s that triggered the transformation of the entire social and political fabric of Europe. Central to these changes was the military and biological invasion of the Amazon region and its surroundings. While formative clues of climate change appeared as early as the 1570 s, by the end of the 16th century the temperatures in Europe plummeted by $2{ }^{\circ} \mathrm{C}$, so drastically that Mediterranean harbours were covered with ice, birds literally dropped out of the sky, and 'frost fairs' were erected on a frozen Thames River-with kiosks, taverns, and even brothels that become a semi-permanent part of the city. This 'Little Ice Age' with its apocalyptic weather patterns destroyed entire harvests and incited mass human migrations giving rise to the growth of European cities, the appearance of early capitalism, and the vigorous stirrings of the Enlightenment (Miller, 2019). Such disruptions in First Nations People's intergeneration management of landscape also flowed into North America (Foster, 2012), and both contributed as also being affected by microclimate changes (Pyne, 1997, 2015).

In a different tract of geography, Gammage (2011) has pointed to the cessation of First Nations People's 'fire-stick farming' (Jones, 2012) management of the Australian continent-'the biggest estate on earth'-with the advent of British military and biological colonization activities in the 1820s-1860s period, in part due to their paranoia about fires destroying their squatting infrastructure and their prized sheep and cattle assets (Pyne and Cronon, 1998). The climate change effects were equally felt in the United Kingdom where temperatures again dropped, crop harvests were affected, inclement weather prevailed negating industrial aerial pollutant dispersal in part disguised the formative environmental and societal ravages of industrialization in central England and lower vale Scotland.

The Amazon Forest has been the subject of countless literary fiction narratives. Therefore, it is of no surprise that the recent fire incidents have caught global attention. This focus denotes the global importance of this tropical rain forest, taunted as the 'lungs' of the earth, given its capability to produce over $20 \%$ of the world's oxygen $\left(\mathrm{O}_{2}\right)$, and in its capacity to store substantial amounts of carbon dioxide $\left(\mathrm{CO}_{2}\right)$. The same forest is said to be home to over $20 \%$ of the global tree species in excess of any other forest in the world, and hosts more terrestrial wildlife, birds, and aquatic life than any other region of the world. Additionally, it is also considered to be the richest ecosystem in terms of natural resources, that are of international recognition. These values have, on the negative side, attracted substantial attention from human invaders with an aim to exploit and capitalize on this rich biodiversity for their own personal and/or corporate selfish benefits.

Tucker (1996) note that such exploitive trends date back to colonialism when European 'explorers' invaded the region and started exploiting its biodiversity resources (e.g., economic botany, horticulture, birds, etc.) dreams of gold (Au) and mythical empires, to supply insatiable European populace scientific pursuits and or collecting passions. More recently, the forest has been under immense pressure from corporate entities, business persons, politicians, and other groups who have perpetuated wanton degradation of the forest through illegal logging, illegal wildlife trade, and other environmental degrading practices (Cowie, 2017). Such degenerative practices are leading to increasing calls for environmental conservation or preservation, including voices from the younger generation who are witnessing first-hand the lost benefits of thriving natural ecosystems.

The forest has also experienced challenges from urbanisation, as more of the land is being cleared and converted into urban areas as local people settle near the forest and draw resources from it. Richards and VanWey (2016) showcase how such urbanisation trends are instigated by global demands for forest tradable products and these have prompted the creation of different infrastructures that allow for the extraction and transportation of resources to different global destinations. Noting this scenario, Sonter et al. (2017) argue that the natural capital and value harbored in the Amazon forest, especially in terms of natural minerals, has resulted in massive losses of the forest coverage, with over $9 \%$ of the forest cover being lost between 2005 and 2012. Most of this loss occurred as a consequence of land clearance to create space for mining activities and its associated infrastructure as well as to accommodate and service the increasing migrant transitory workers who want to partake in the numerous economic and human activities enabled by the forest resources.

The recent fires in the Amazon forests are just the tipping point for the numerous but rarely spoken about challenges that the forests have witnessed throughout their contemporary history. From diverse global centres, experts are attributing these fires to human-induced activities, while others are pointing an accusing finger to climate-change-induced environmental conditions. As shown in Figs. 1 and 2, the fires have spread rather rapidly, when this is compared to other fires from previous years, where this ravaged wilderness areas. The fast pace of fire dispersal and spread is additionally ecologically disruptive in its own right in negating the successional regenerational composition and response of this extant rich biodiversity. Woodward (2019) reports that the over 76,000 fire incidences in 2019 are almost double what was statistically experienced in 2018 alone which experienced only 40,000 fires. Therefore, Cammelli and Angelsen (2019) argue that these thousands of fires are causing irreversible damage not only in the forest's ecosystem but upon the region and also on a global scale. These forest ecosystem damages not only implicate the biodiversity and the environment but also implicate political spheres, where there is already evidence of escalating political tensions between international groups, nations, First Nations People's and local governments in combating the ravaging fires.

Disregarding the local and international geopolitical politics that this fire has sparked; the conventional argument has been that external politics should not interfere in local policies. As in local politics enable and supports economically to local welfare of both the communities and the forests (Meyer, 2019). In addition, the repeated international calls for speedy action, and unsolicited assistance being offered to the Brazilian government is internally criticized as being insincere, poli-exploitive, as most of the countries extending help, and advocating for forest protection, have equally been criticized as being the leaders of our emissions generation. Thus, they are subtly attempting to shift ecoresponsibility to lesser more compliant voices in their efforts to combat global climate change. With this argument, it behoves the Brazilian government to establish and implement strengthened policies that focus on the conservation of the forests, as well as protecting the First Nations Peoples who live in the forests and the rich diversity of wildlife that teem inside this larger ecosystem.

Ensuring appropriate policy responses to conserving the Amazon Forest is apparent in terms of the preservation of cultural attributes and policies towards global public good and carbon sequestration. The quantitative analysis highlights that the opportunity cost can amount to an average of USD\$797 per ha of land (Silva et al., 2019). However, it has been noted that investments to save the Amazon Forest fires can amount up to 50 times less (Lapola et al., 2018), positing that significant cost savings can be achieved in terms of alternative policies and that there is a need to review structures at both local and global levels.

As much as local policies work towards balancing economic growth and environmental conservation, the latter should take 


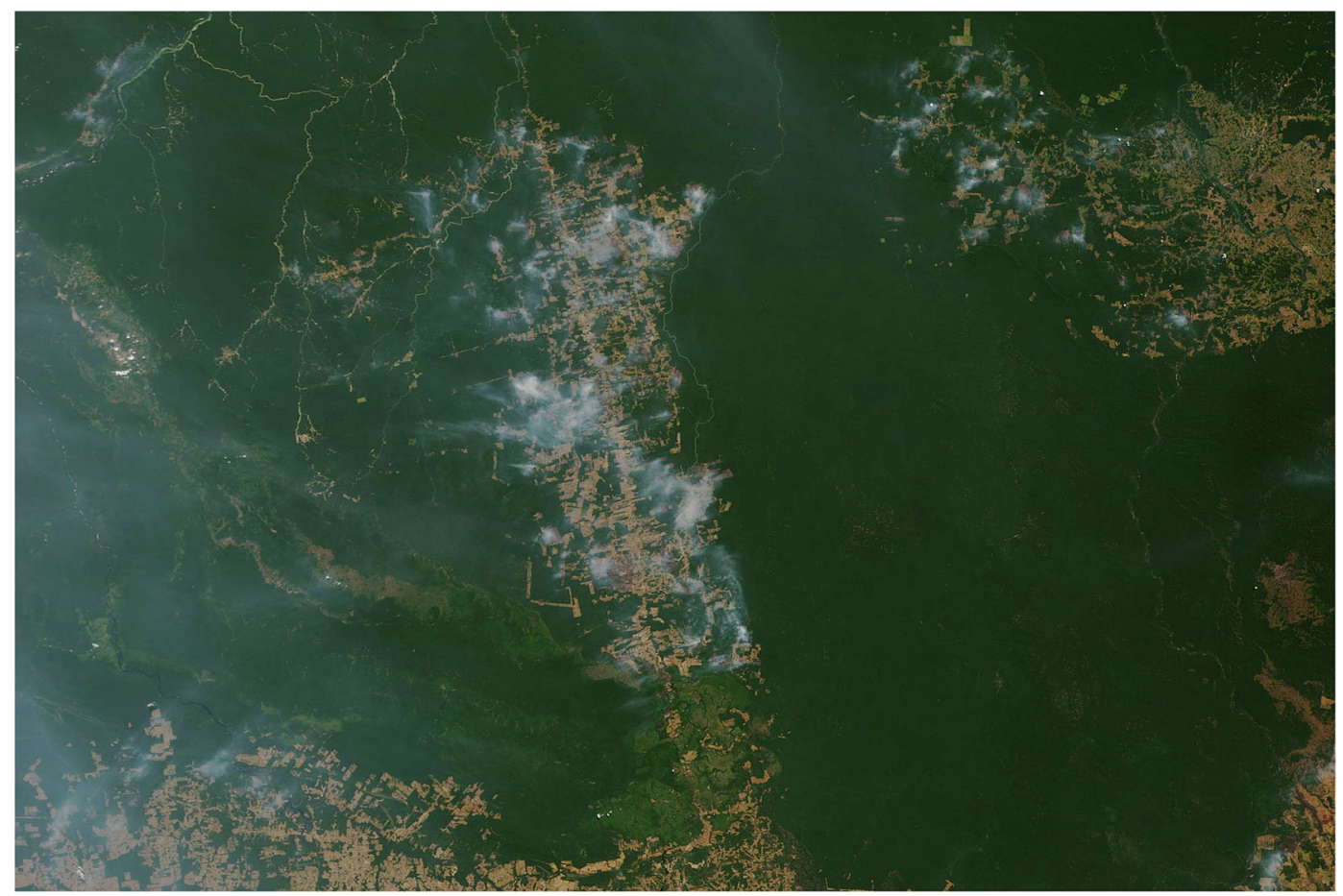

Fig. 1 Space photograph for forest fires. Depicting intensity and rapid spread of fires in the Amazon Forest. Image by Stevens (2019), sourced from NASA's Earth Observatory, under a CC BY license.

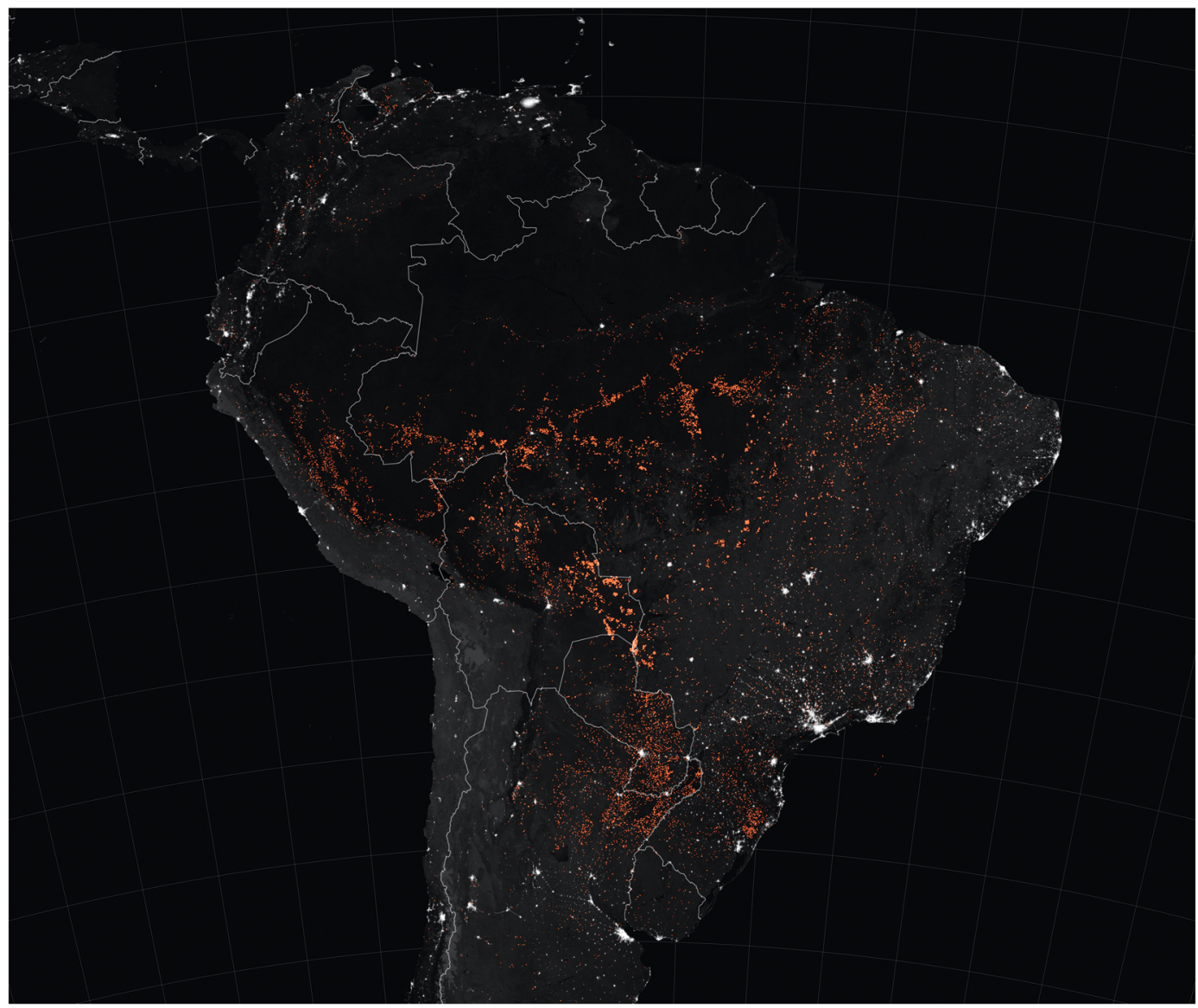

Fig. 2 Mapping of forest fires. Fire detections from August 15 to 22, from NASA's Moderate Resolution Imaging Spectroradiometer (MODIS). Image by Stevens (2019) and sourced from NASA's Earth Observatory, under a CC BY license. 
precedence as the entire planetary ecosystem relies on its health and vitality. Such efforts could benefit from applying an integrated ecosystem accounting model that streamlines both economic and human benefits and considers the welfare of the larger planetary ecosystem.

\section{The global ecosystem accounting model}

An environment of disbalance is evident in polluting countries (those that are effectively contributing to climate change) who are seeking to influence the politics of least developing economies thereby passively and subtly attempting to economically control foreign sovereignties. Within this shadow, the responsiveness of the Brazilian government in rejecting 'foreign' assistance (BBC, 2019) is understood.

This is not saying that the Brazilian government denies, morally, the contribution of the forest to the planet's ecological systems and does not recognise the consequences thereof when the Amazon Forest is destroyed. But rather they are questioning the motivations as to why the financial assistance was being advanced in the first place. On face value, such a gesture should be welcomed, as the forests host priceless resources that merit obvious conservation efforts, but there are notable arguments in hindsight for this assistance. This is affirmed by far-right leader Brazilian president, Jair Bolsonaro, who argues that some of the members of the G7 Coalition (Canada, France, Germany, Italy, Japan, the United Kingdom and the United States; France in particular) were more concerned about their agricultural competition 'war' with Brazil, and the economic calamity faced by G7 competition policies that are seeking to maintain their artificial competitiveness (Togoh, 2019). Recognizing that the G7 comprises some of the largest polluters, their financial support can be argued as arising from their internal economic concerns as such offers were tabled well past the advent of the forest fires. While it is also valid to state that these countries are also active consumers of some of the products derived from the rainforest, they do face internal political pressures emanating from pressures upon these countries' domestic markets. Nevertheless, there is a need for a more robust framework accompanied by active policies on planetary ecosystem management and conservation to ensure a more cohesive and globally sustainable approach.

Figure 3 introduces a Global Ecosystem Accounting Model. The concept supports an economic accounting of various assets to achieve ecosystem conservation, on the basis that

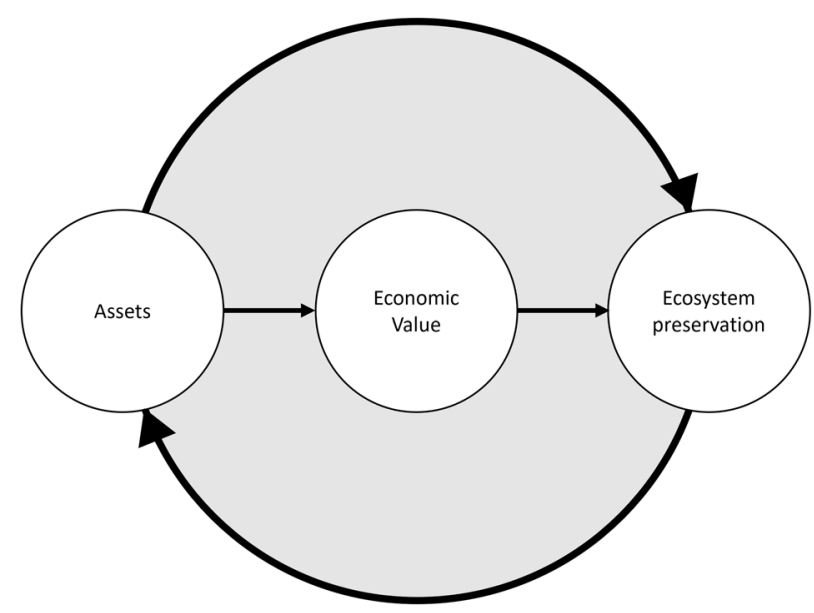

Fig. 3 Global ecosystem accounting model. Proposed model underlines that assets, provided with an economic value, can lead to ecosystem preservation. Illustration by authors, available for re-use. developments could be hindered on ecologically important assets as there would be an economic value being paid to ensure their conservation. This is further discussed in the following section.

\section{Discussion}

The above model is predicated upon the premise that every ecological asset that brings an added value to the global planetary ecosystem needs to be weighted economically. Thus, there is a need to construct a formula to ensure that conservation is the subject of contribution and global management agreements. This model departs from previous ecosystem accounting models by treating ecological assets as being localized. While past advocates and researchers have promulgated the need to find alternate ecosystem accounting models, few have unpacked and conceptualised an alternate model as discussed in this paper. The past advocates and researchers recognize that their accounting systems are limited to geographical boundaries, and thus, the global audience (or group of countries) has had little or no direct influence on conservation actions. However, the model proposal tabled here does not remove the authority of local governments in the management and conservation of natural resources within their jurisdictions. On the contrary, it opens doors for the global community to participate and take responsibility in the protection of these assets, which are part of the global planetary ecosystem principles.

Against the above background, local authorities would be discouraged or limited in allowing developments or engagements of different economic activities inside ecologically sensitive zones, as such would be compensated economically in protecting them. Ecologically sensitive zones require special attention as there are biodiversity niches containing key systems that are representative of past and existing biodiversity profiles but also are witnessing a natural evolutional change in response to both time and climate change. Such niches require additional valuable and weighted escalating scales rather than the conventional equal values. The compensation price tag aligns with the premise of a land lease agreement, where the ecological assets in question would be leased to a global entity, and recompensation paid on a regular basis. The positive aspect of this approach is that it would curtail any fraudulent practices, rent-seeking behaviour or political influence on the part of local governments when dealing with resources narrated as being 'of global importance' as the global community would have an influence on how activities in local ecosystems are conducted.

In the same vein, as noted above, the responsibility of protecting sensitive areas, like the Amazon Forests, would still be vested upon the shoulders of local authorities while still enabling the indirect participation of the global community. This approach thereby calls for the use of more efficient and advanced equipment, infrastructures and technologies, and with the global community being part of the participants these mechanisms would obviously be subsidized by global efforts. This is particularly important, especially in discouraging the illegal demand of ecological resources, like wildlife and their products, where there would be concerted efforts to negate illegal forms of trade within or outside the borders of the ecologically sensitive areas. The same approach would also allow local governments to capitalize on their ecological assets as these would be seen as revenue-generating areas and assets where a return in value would be borne by the global community.

This approach could further lead to reinforcing protection and on-ground 'policing' measures by local authorities towards illegal ecological resource extraction from protected areas. This is because, together with global actors, they would be able to 
better address loopholes in regional policies which arise with trade between two or more jurisdictions and to delimit black markets that encourage illegal practices. On this, local governments would not feel short or undermined when global assistance is offered like what was evident in the recent case between the G7 coalition and the Brazilian Government (Marshall, 2019).

While the above is paramount, it should not be lost that the economic weightage of ecologically sensitive assets is a difficult topic to quantify (Ogilvy, 2015). For instance, with climate change, the values keep increasing as the impacts, mainly fueled by rapid urbanization and demographic booms, take a toll on those values (Rannow et al., 2014; Rohr et al., 2013). The economic quantification of these values is of a further challenge when recognizing that computing the impacts of climate change is not uniform across regions, rendering inconsistencies in valuation prices. Nevertheless, adopting a global economically inclined model, like the one proposed above, to natural resource management would lead to concrete and long-lasting solutions that could transcend physical boundaries and avoid geopolitical influences on foreign matters. Adopting the above planetary ecosystem accounting model could mean that ecological assets are valued almost uniformly across the globe. Hence, attention given to them would be similar regardless of the geographical location would receive global attention without being dragged or derailed by geopolitical influences or disagreements.

On a broader scale, when it comes to the planetary ecosystem and ecological assets, there is a need to adopt a global outlook, although may deem to be a local issue, always has far reaching impacts on the global context (Kattumuri, 2017). Recognising that there have been disasters in different global ecosystems, the Amazon Forest fires offer a precedent pointer as to how much the global ecosystem can be affected when the management and conservation efforts of ecological assets of global magnitudes are micro-managed without the input of the global community that benefits or suffers directly from any action or inaction on a major ecosystem. The rapid spread of the Amazon Forest fires has exposed the limitations of geographically based ecosystem accounting models and has prompted the need for models like the one proposed above to cater to a larger global context.

\section{Conclusion}

This paper explores the literature on ecosystem management and underlines how such existing tools prompt geopolitical influences, creating tensions, and putting at risk ecologically sensitive areas. The case of the Amazon Forest fires is explored within the context of a landscape of unfairness when sovereign-polluting countries advocate for environmental conservation external to their physical jurisdictional boundaries. Diaz's voice, quoted above, is a voice from the groundlevel, but carries little weight in an upper-level controlled ecopolitical system, so such First Nation's People's voices need credible applied science to support and validate their longstanding intergenerational responsibilities. While this is historically a recurrent geopolitical issue, this paper offers a perspective on how natural resources and ecologically sensitive areas, that benefit the global community, can be more effectively managed and accounted for through a proposed Global Planetary Ecosystem Accounting Model that could better enable their conservation through the lens of a revenuegenerating activity.
Received: 18 January 2021; Accepted: 12 October 2021; Published online: 28 October 2021

\section{References}

Ajani JI, Keith H, Blakers M, Mackey BG, King HP (2013) Comprehensive carbon stock and flow accounting: a national framework to support climate change mitigation policy. Ecol Econ 89:61-72. https://doi.org/10.1016/ j.ecolecon.2013.01.010

Bartelmus P (2015) Do we need ecosystem accounts? Ecol Econ 118:292-298 https://doi.org/10.1016/j.ecolecon.2014.12.026

BBC (2019) Amazon fires: Brazil to reject G7 offer of \$22m aid. BBC News https:// www.bbc.com/news/world-latin-america-49479470. Accessed 28 Aug 2019

Blom P (2019) Nature's Mutiny: how the little ice age transformed the west and shaped the present. Pan Macmillan

Bockstael N, Freeman AM, Kopp RJ, Portney PR, Smith VK (2000) On measuring economic values for nature. Environ Sci Technol 34:1384-1389

Cammelli F, Angelsen A (2019) Amazonian farmers' response to fire policies and climate change. Ecol Econ 165:106359. https://doi.org/10.1016/ j.ecolecon.2019.106359

Cazalis V, Loreau M, Henderson K (2018) Do we have to choose between feeding the human population and conserving nature? Modelling the global dependence of people on ecosystem services. Sci Total Environ 634:1463-1474. https://doi.org/10.1016/j.scitotenv.2018.03.360

Cowie S (2017) Brazil's worst month ever for forest fires blamed on human activities. The Guardian https://www.theguardian.com/world/2017/sep/28/ brazil-forest-fires-deforestation-september-record-amazon. Accessed 28 Aug 2019

Edens B, Hein L (2013) Towards a consistent approach for ecosystem accounting. Ecol Econ 90:41-52. https://doi.org/10.1016/j.ecolecon.2013.03.003

Ellison D, Lundblad M, Petersson H (2011) Carbon accounting and the climate politics of forestry. Environ Sci Policy 14(8):1062-1078. https://doi.org/ 10.1016/j.envsci.2011.07.001

Eriksson FA (2018) Denmark's Green National Accounting Framework in support of the sustainable development goals. Joint OECD/UNECE seminar on implementation of SEEA, Geneva

Foster WC (2012) Climate and culture change in North America AD 900-1600. University of Texas Press

Gammage B (2011) The Biggest Estate on Earth: how Aborigines made Australia. Allen \& Unwin

Hein L, Bagstad K, Edens B, Obst C, de Jong R, Lesschen JP (2016) Defining ecosystem assets for natural capital accounting. PLoS ONE 11(11):e0164460. https://doi.org/10.1371/journal.pone. 0164460

IPCC (2021) Climate Change 2021: the physical science basis. Contribution of Working Group I to the Sixth Assessment Report of the Intergovernmental Panel on Climate Change. Cambridge University Press

IRENA (2018) Global energy transformation: a roadmap to 2050. International Renewable Energy Agency

Jones R (2012) Fire-stick farming. Fire Ecol 8(3):3-8. https://doi.org/10.1007/ BF03400623

Kattumuri R (2017) Sustaining natural resources in a changing environment: evidence, policy and impact. Contemp Soc Sci 13(1):1-16. https://doi.org/ $10.1080 / 21582041.2017 .1418903$

Kelsey N, Meckling J (2018) Who wins in renewable energy? Evidence from Europe and the United States. Energy Res Soc Sci 37:65-73

La Notte A, Vallecillo S, Marques A, Maes J (2019) Beyond the economic boundaries to account for ecosystem services. Ecosyst Serv 35:116-129. https://doi.org/10.1016/j.ecoser.2018.12.007

Lapola DM, Pinho P, Quesada CA, Strassburg BBN, Rammig A, Kruijt B, Brown F, Ometto JPHB, Premebida A, Marengo JA, Vergara W, Nobre CA (2018) Limiting the high impacts of Amazon forest dieback with no-regrets science and policy action. Proc Natl Acad Sci USA 115(46), 11671. https://doi.org/ 10.1073/pnas.1721770115

Lomas PL, Giampietro M (2017) Environmental accounting for ecosystem conservation: linking societal adn ecosystem metabolisms. Ecol Model 346:10-19. https://doi.org/10.1016/j.ecolmodel.2016.12.009

Lowenthal D (1975) Past time, present place: landscape and memory. Geogr Rev 65(1):1-36. https://doi.org/10.2307/213831

Mace GM (2019) The ecology of natural capital accounting. Oxf Rev Econ Policy 35(1):54-67. https://doi.org/10.1093/oxrep/gry023

Mace GM, Norris K, Fitter AH (2012) Biodiversity and ecosystem services: a multilayered relationship. Trends Ecol Evol 27(1):19-26

Mäler G, Aniyar S, Jansson A (2008) Accounting for ecosystem services as a way to understand the requirements for sustainable development. Proc Natl Acad Sci USA 105(28), 9501-9506 https://doi.org/10.1073/pnas.0708856105 
Marshall E (2019) Bolsanaro says Macron must take back 'insults' for Brazil to accept 57 Amazon aid. Telegraph https://www.telegraph.co.uk/news/2019/08/ 27/brazil-rejects-g7-aid-amazon-fires-saying-funds-relevant-reforest/. Accessed 28 Aug 2019

Mazzucato M, Semieniuk G (2018) Financing renewable energy: Who is financing what and what it matters. Technol Forecast Soc Change 127:8-22. https:// doi.org/10.1016/j.techfore.2017.05.021

Meyer R (2019) The Amazon cannot be recovered once it's gone. Atlantic https:// www.theatlantic.com/science/archive/2019/08/amazon-fires-are-political/ 596776/. Accessed 28 Aug 2019

Miller P (2019) Climate change and human history. N Y Times https:// www.nytimes.com/2019/03/05/books/review/philipp-blom-naturesmutiny.html. Accessed 23 Aug 2021

Moloney A (2021) Tribes launch bid to protect Amazon forest at global conservation forum. Age https://www.theage.com.au/world/south-america/ tribes-launch-bid-to-protect-amazon-forest-at-global-conservation-forum20210827-p58mkt.html. Accessed 29 Aug 2021

Notte AL, Dalmazzone S (2018) Sustainability assessment and causality nexus through ecosystem service accounting: the case of water purification in Europe. J Environ Manag 223:964-974. https://doi.org/10.1016/j.jenvman.2018.06.072

Ogilvy S (2015) Developing the ecological balance sheet for agricultural sustainability. Sustain Account Manag Policy J 6(2):110-137. https://doi.org/ 10.1108/SAMPJ-07-2014-0040

Pyne SJ (1997) Vestal fire an environmental history, told through fire, of Europe and Europe's encounter with the world. University of Washington Press

Pyne SJ (2015) Between two fires a fire history of contemporary America. University of Arizona Press

Pyne SJ, Cronon W (1998) Burning bush: a fire history of Australia. http:// site.ebrary.com/id/11137376

Rannow S, Mcgregor NA, Albrecht I, Crick HQ, Forster M, Heiland S, Janauer G, Morecroft MD, Neubert M, Sarbu A, Sienkiewicz J (2014) Managing protected areas under climate change: challenges and priorities. Pubmed 54(4):732-743. https://doi.org/10.1007/s00267-014-0271-5

Richards P, VanWey L (2016) Where deforestation leads to urbanization: how resource extraction is leading to urban growth in the Brazilian Amazon. HHS Public Access 105(4):806-823. https://doi.org/10.1080/00045608.2015.1052337

Rohr JR, Johnson P, Hickey CW, Helm RC, Fritz A, Brasfield S (2013) Implications of global climate change for natural resource damage assessment, restoration, and rehabilitation. Environ Toxicol Chem 32(1):93-101. https://doi.org/ $10.1002 /$ etc. 2036

Ruijs A, Van der Heide M, Van den Berg J (2018) Natural capital accounting for the sustainable development goals. P.N.E.A. Agency

Salazar-Lopez L, Allen L (2019) We are facing a global emergency in the Amazon. Here's what we can do. CNN. https:/edition.cnn.com/2019/08/24/opinions/ global-emergency-in-the-amazon-salazar-lopez-allen/index.html. Accessed 28 Aug 2019

Scott D, Hall CM, Gössling S (2016) A report on the Paris Climate Change Agreement and its implications for tourism: why we will always have Paris. J Sustain Tour 24(7):933-948

Silva FdF, Perrin RK, Fulginiti LE (2019) The opportunity cost of preserving the Brazilian Amazon forest. Agric Econ 50(2):219-227. https://doi.org/10.1111/ agec. 12478

Sonter LJ, Herrera D, Barrett DJ, Galford GL, Moran CJ, Soares-Filho BS (2017) Mining drives extensive deforestation in the Brazilian Amazon. Nation Commun 8(1):1013. https://doi.org/10.1038/s41467-017-00557-w

Stevens J (2019) Uptick in Amazon fire activity in 2019. NASA Earth Observatory. https:/earthobservatory.nasa.gov/images/145498/uptick-in-amazon-fireactivity-in-2019. Accessed 29 Aug 2021

Symbol of Statistics Canada (2018) Ecosystem accounting. Symbol of statistics Canada. https://www150.statcan.gc.ca/n1/pub/16-509-x/2016001/7-eng.htm. Accessed 28 Aug 2021

Tajrin S, Hossain B (2018) Rural-Urban migration and its causes and consequences on Migrant Street Hawker in Khulna City. Int J Humanit Soc Stud 7:223-236

Taylor K (2017) Landscape, culture and heritage. Changing perspectives in an Asian context. Ph.D. thesis, Deakin University

Togoh I (2019) Brazilian President Blames political motives for Amazon Fires as Macron warns 'our house is burning'. Forbes. https://www.forbes.com/sites/ isabeltogoh/2019/08/23/bolsonaro-blames-political-motives-for-amazonfires-as-macron-warns-our-house-is-burning-down/\#3272c2ca24d5. Accessed 28 Aug 2019

Tu Y (2017) Urban debates for climate change after the Kyoto Protocol. Urban Stud 55(1):3-18. https://doi.org/10.1177/0042098017717363.

Tucker CM (1996) Traditional peoples and the struggle for land in the Amazon Basin. Arizona Anthropol 12:123-149
UN (2014) System of environmental-economic accounting 2012 Central Framework. W. B. United Nations

UN (2018) The role of the system of environmental-economic accounting as a measurement framework in support of the post-2020 Agenda. S.o.E.E. Accounting

UN (2020) How natural capital accounting contributes to integrated policies for sustianability. https://seea.un.org/sites/seea.un.org/files/seea_-_overview__web_ready.pdf

United Nations (2018a) The World's Cities in 2018-Data Booklet. United Nations

United Nations (2018b) World urbanization prospects-the 2018 revision. Population Division, United Nations

USAID/NREL (2018) Greening the grid: Solar and Wind Grid Integration Study for the Luzon-Visayas System on the Philippines. USAID/NREL

Vačkářů D, Grammatikopoulou I (2018) Toward development of ecosystem asset accounts at the national level. Ecosyst Health Sustain 5(1):36-46. https:// doi.org/10.1080/20964129.2018.1560233

Vallecillo S, La Notte A, Zulian G, Ferrini S, Maes J (2019) Ecosystem services accounts: valuing the actual flow of nature-based recreation from ecosystems to people. Ecol Model 392:196-211. https://doi.org/10.1016/ j.ecolmodel.2018.09.023

Vargas L, Willemen L, Hein L (2018) Linking planetary boundaries and ecosystem accounting, with an illustration for the Colombian Orinoco river basin. Reg Environ Change 18(5):1521-1534

Watts J (2019). Amazon rainforest fires: global leaders urged to divert Brazil from 'suicide' path. Guardian. https://www.theguardian.com/environment/2019/ aug/23/amazon-fires-global-leaders-urged-divert-brazil-suicide-path. Accessed 28 Aug 2019

Woodward A (2019). The Amazon is burning at a rate not seen since we started keeping track. The smoke is reaching cities 2000 miles away. Business Insider. https://www.pulselive.co.ke/bi/tech/the-amazon-is-burning-at-a-rate-notseen-since-we-started-keeping-track-the-smoke-is/xz3pyb5. Accessed 28 Aug 2019

Yang Q, Liu G, Casazza M, Campbell ET, Giannetti BF, Brown MT (2018) Development of a new framework for non-monetary accounting on ecosystem services valuation. Ecosyst Serv 34:37-54. https://doi.org/10.1016/ j.ecoser.2018.09.006

Zhang Y-X, Chao Q-C, Zheng Q-H, Huanga L (2017) The withdrawal of the U.S from the Paris Agreement and its impact on global climate change governance. Adv Clim Change Res 8(4):213-219. https://doi.org/10.1016/ j.accre.2017.08.005

Zhou Z, Ou J, Li S (2016) Ecological accounting: a research review and conceptual framework. J Environ Prot 07:643-655. https://doi.org/10.4236/ jep.2016.75058

\section{Competing interests}

The authors declare no competing interests.

\section{Additional information}

Correspondence and requests for materials should be addressed to Zaheer Allam.

Reprints and permission information is available at http://www.nature.com/reprints

Publisher's note Springer Nature remains neutral with regard to jurisdictional claims in published maps and institutional affiliations.

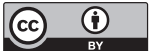

Open Access This article is licensed under a Creative Commons Attribution 4.0 International License, which permits use, sharing adaptation, distribution and reproduction in any medium or format, as long as you give appropriate credit to the original author(s) and the source, provide a link to the Creative Commons license, and indicate if changes were made. The images or other third party material in this article are included in the article's Creative Commons license, unless indicated otherwise in a credit line to the material. If material is not included in the article's Creative Commons license and your intended use is not permitted by statutory regulation or exceeds the permitted use, you will need to obtain permission directly from the copyright holder. To view a copy of this license, visit http://creativecommons.org/ licenses/by/4.0/.

(c) The Author(s) 2021 